\title{
The 1,4 benzoquinone-featured 5- lipoxygenase inhibitor RF-Id induces apoptotic death through downregulation of IAPs in human glioblastoma cells
}

\author{
S. Zappavigna ${ }^{1}$, M. Scuotto ${ }^{2}$, A. M. Cossu' ${ }^{1}$ D. Ingrosso ${ }^{1}$, M. De Rosa ${ }^{2}$, C. Schiraldi ${ }^{2}$, R. Filosa ${ }^{2^{*}}$ and M. Caraglia ${ }^{1^{*}}$
}

\begin{abstract}
Background: Embelin is a potent dual inhibitor of 5-lipoxigenase (5-LOX) and microsomal prostaglandin E2 synthase (mPGES)-1 that suppresses proliferation of human glioma cells and induces apoptosis by inhibiting XIAP and NF-KB signaling pathway. Synthetic structural modification yielded the derivative 3-((decahydronaphthalen-6-yl)methyl)-2,5dihydroxycyclohexa-2,5-diene-1,4-dione (RF-Id), an embelin constrained analogue, with improved efficiency against 5LOX in human neutrophils and anti-inflammatory activity in vivo. Taking into account that lipoxygenase (LOX) metabolites, from arachidonic acid and linoleic acid, have been implicated in tumor progression, here, we determined whether RF-Id was able to hinder glioblastoma (GBM) cancer cell growth and the related mechanisms.
\end{abstract}

Methods: U87MG and LN229 cells were plated in 96-wells and treated with increasing concentrations of RF-ld. Cell viability was evaluated by MTT assay. The effects of the compounds on cell cycle, apoptosis, oxidative stress and autophagy were assessed by flow cytometry (FACS). The mode of action was confirmed by Taqman apoptosis array and evaluating caspase cascade and NFKB pathway by western blotting technique.

Results: Here, we found that RF-Id induced a stronger inhibition of GBM cell growth than treatment with embelin. Flow cytometry analysis showed that RF-Id induced about $30 \%$ apoptosis and a slight increase of autophagy after $72 \mathrm{~h}$ on U87-MG cells. Moreover, the compound induced an increase in the percentage of cells in G2 and S phase that was paralleled by an increase of p21 and p27 expression but no significant changes of the mitochondrial membrane potential; array analysis showed a significant upregulation of CASP8 and a downregulation of IAP family and NFKB genes in cells treated with RF-Id. RF-Id induced a significant cleavage of caspases 8, 9, 3 and 7, blocked c-IAP2/XIAP interaction by inducing XIAP degradation and inhibited NFKB pathway.

Conclusions: RF-ld induced a caspase-dependent apoptosis in GBM cells by inhibiting IAP family proteins and NFkB pathway and represents a promising lead compound for designing a new class of anti-cancer drugs with multiple targets.

Keywords: Apoptosis, Glioblastoma, IAPs, NFkB, RF-Id

\footnotetext{
* Correspondence: rosanna.filosa@unina2.it; michele.caraglia@unina2.it ${ }^{2}$ Department of Experimental Medicine, Second University of Naples, Via L. De Crecchio, 7, Naples 80138, Italy

'Department of Biochemistry, Biophysics and General Pathology, Second University of Naples, via L. De Crecchio 7, Naples 80138, Italy
} 


\section{Background}

Glioblastoma multiforme (GBM) is the most common and deadliest of malignant primary brain tumors in adults. Combination of radiotherapy and temozolomide (TMZ) represents the gold-standard first-line treatment for GBM $[1,2]$. In recent phase II trials, also nitrosoureas such as fotemustine (FTM) have shown mild activity for recurrent GBM [3, 4]. The blood-brain barrier (BBB) is the most important limiting factor for the development of new drugs and drug delivery for the central nervous system (CNS) [5]. In this context, we showed that the newly developed transferrin (Tf)-targeted self-assembling nanoparticles (NPs) incorporating zoledronic acid (ZOL) allowed the successfully use of ZOL in the treatment of GBM, potentiating its in vitro and in vivo antitumor activity on GBM through the acquisition of ability to cross the BBB [6].

Despite the aggressive first-line therapy and the recent results with surgery, radiation therapy and adjuvant chemotherapy, tumors invariably recur and median survival is 15 months [7]. Further progress towards a cure for malignant gliomas will require a greater understanding of the underlying mechanisms driving the growth and resistance to therapy of these tumors.

In this framework, it is well established that many cancers derive from sites of chronic inflammation; the tumor environment, which is orchestrated by the interplay between inflammatory cells, tumor cells, and other tumorassociated host cells, is an essential member in the tumorigenic progression. Cancer and inflammation are intimately linked due to specific oxidative processes in the tumor microenvironment.

In this context, the pro-inflammatory microenviroment in various human brain tumors is characterized by high expression of 5-Lipoxygenases (5-LOX) [8], a versatile class of oxidative enzymes involved in arachidonic acid metabolism, that promote the proliferation of glioma cells [9-12]. In addition, is well recognized that the inhibitors of 5-LOX can activate Caspase-3 inducing glioma cell apoptosis, suggesting that 5-LOX can participate in the survival of glioma cells [13]. In this context NDGA, a natural 5-LOX inhibitor, and its methylated derivative, terameprocol, exhibited anticancer activity; moreover, terameprocol is a global transcription inhibitor that affects cell division, apoptosis, drug resistance, hypoxia responsive genes, and radiation resistance in hypoxia. Previous research indicated terameprocol as a drug that could be safely combined with radiation in newly diagnosed high-grade glioma [14].

Starting from these considerations, as cancer is a multifactor disease, there is great interest in the development of new compounds able to target multiple intracellular components.

Our group have been interested for a long time in the synthesis and the biological evaluation of anti-cancer and anti-inflammatory agents including quinone-based compounds [15-26]. Within the context of our investigations towards the synthesis of quinone derivatives with prospects for therapeutic use, we recently studied the natural compound embelin, a potent dual inhibitor [18] of 5-lipoxigenase (5-LOX) and microsomal prostaglandin E2 synthase (mPGES)-1 able to suppress proliferation of human glioma cells and to induce apoptosis by inhibiting XIAP and NF-kB signaling pathway [27-29].

Moreover, we have previously discovered (RF-Id), an embelin constrained analogue, with improved efficiency against 5-LOX in human neutrophils and antiinflammatory activity in vivo $[15,19]$, and the aim of the present study was to determine the precise cellular mechanisms of the new 5-LOX inhibitor RF-Id and verify its intrinsic inhibition of XIAP function.

\section{Methods \\ Materials}

All reagents were analytical grade and purchased from Sigma Aldrich (Milano, Italy). RPMI, DMEM were purchased from Life Technologies (Carlsbad, CA) supplemented with $10 \%$ FBS (fetal bovine serum), $1 \%$ penicillin, streptomycin and L-glutamine from Lonza Group Ltd (Svizzera). The rabbit antibodies raised against $\alpha$-tubulin, caspase-3, detecting endogenous levels of full length caspase-3 (35 kDa) and the large fragment of caspase-3 resulting from cleavage $(17 \mathrm{kDa})$; caspase-8, detecting endogenous level of total caspase-8 $(57 \mathrm{kDa})$, including the p10 subnit of the activated protein; caspase-9, detecting endogenous levels of full length caspase-9 (47 kDa), a large fragment $(35 \mathrm{kDa}$ or $17 \mathrm{kDa}$ ) and a small fragment $(10 \mathrm{kDa})$ of caspase-9 resulting from cleavage; p21, p27, XIAP, C-IAP-2, $\mathrm{pIKK} \alpha / \beta, \mathrm{IKK} \alpha / \beta, \mathrm{pIKB} \alpha, \mathrm{IKB} \alpha$ and $\mathrm{p} 65$ subunit of $\mathrm{NF}_{\kappa} B$ were purchased by Cell Signaling Technology. The rabbit antibody raised against caspase -7 detecting endogenous levels of full length caspase-7 (34 kDa) was purchased by Santa Cruz Biotechnology.

\section{Chemistry}

The compound RF-Id was synthesized and characterized as reported previously [18]. RF-1d-met was prepared starting from 1,2,4,5-tetramethoxybenzene and decahydronaphthalene-2-carbaldehyde. Coupling the above aldehyde with the lithium anion of 1,2,4,5-tetramethoxybenzene (2.5 equiv of $\mathrm{BuLi}, \mathrm{THF}$ ) afforded compound RF-1d-met as a mixture of diastereomers in $65 \%$ yield.

\section{Cell culture}

Human GBM cell lines U87MG and LN229 were provided by Dr. Carlo Leonetti (Regina Elena Cancer Institute, Rome, Italy). U87MG and LN229 cells were grown in RPMI and DMEM, respectively, supplemented with 
$10 \%$ heat-inactivated fetal bovine serum, $20 \mathrm{mM}$ HEPES, $100 \mathrm{U} / \mathrm{mL}$ penicillin, $100 \mathrm{mg} / \mathrm{mL}$ streptomycin, $1 \% \mathrm{~L}$-glutamine and $1 \%$ sodium pyruvate. Cells were cultured at $37{ }^{\circ} \mathrm{C}$ in a $5 \% \mathrm{CO}_{2}-95 \%$ air environment in a humidified incubator.

\section{Cell proliferation assay}

Cells were seeded in serum-containing media in 96-well plates at the density of $2 \times 10^{3}$ cells/well. After $24 \mathrm{~h}$ incubation at $37^{\circ} \mathrm{C}$, cells were treated with increasing concentrations of RF-Id, embelin and reference compounds $(0,8-100 \mu \mathrm{M})$ for $24 \mathrm{~h}, 48 \mathrm{~h}$ and $72 \mathrm{~h}$. Cell viability was assessed by adding MTT [3-(4,5-dimethylthiazol-2-yl)-2,5diphenyl tetrazolium bromide] solution in phosphatebuffered saline (PBS) to a final concentration of $5 \mathrm{mg} / \mathrm{mL}$. The plates were then incubated at $37{ }^{\circ} \mathrm{C}$ for an additional $4 \mathrm{~h}$ and the MTT-formazan crystals were solubilized in $1 \mathrm{~N}$ isopropanol/hydrochloric acid $10 \%$ solution at $37{ }^{\circ} \mathrm{C}$ on a shaking table for $20 \mathrm{~min}$. The absorbance values of the solution in each well were measured at $570 \mathrm{~nm}$ using a Bio-Rad 550 microplate reader (Bio-Rad Laboratories, Milan, Italy). Percentage of cell viability was calculated as the following formula (absorbance of the treated wells absorbance of the blank control wells)/(absorbance of the negative control wells - absorbance of the blank control wells). All MTT experiments were performed in quadruplicate.

\section{Flow cytometric analysis of cell cycle}

U87MG cells were seeded in 6-well plates in a number of $2 \times 10^{5}$ cells per well and were treated $24 \mathrm{~h}$ later with the concentration inhibiting $50 \%$ of cell growth (IC:50) of RF- Id. After $72 \mathrm{~h}$ of treatment, cells were washed in PBS and directly stained in a PI solution (50 $\mu \mathrm{g}$ PI in $0.1 \%$ sodium citrate, $0.1 \% \mathrm{NP} 40, \mathrm{pH} 7.4$ ) for $30 \mathrm{~min}$ at $4{ }^{\circ} \mathrm{C}$ in the dark. Flow cytometry analysis was performed using a BD Accuri ${ }^{\text {Tn }}$ C6 (Becton Dickinson). To evaluate cell cycle, PI fluorescence was collected as FL3 (linear scale) by the ModFIT software (Becton Dickinson). For the evaluation of intracellular DNA content, at least 20,000 events for each point were analyzed in at least three different experiments giving a SD less than $5 \%$.

\section{Flow cytometric analysis of apoptosis}

Apoptotic cell death was analysed by Annexin-V-FITC staining and by propidium iodide (PI) detection systems (eBioscences, Vienna, Austria). Briefly, U87MG cells were seeded in 6-well plates in a number of $2 \times 10^{5}$ cells per well and were treated $24 \mathrm{~h}$ later with Rf-Id IC:50. After $72 \mathrm{~h}$ of treatment cells were trypsinezed, washed twice with PBS $1 \mathrm{X}$ and pellets were resuspended in $200 \mu \mathrm{L}$ Binding Buffer 1X. Then, $5 \mu \mathrm{L}$ Annexin V-FITC were added to $195 \mu \mathrm{L}$ cell suspension, mixed and incubated for $10 \mathrm{~min}$ at room temperature. Cells were washed with $200 \mu \mathrm{L}$ Binding Buffer $1 \times$, resuspended in $190 \mu \mathrm{L}$ Binding buffer $1 \times$ and $10 \mu \mathrm{L}$ Propidium Iodide $(20 \mu \mathrm{g} / \mathrm{mL})$ was added. The detection of viable cells, early apoptosis cells, late apoptosis cells and necrotic cells were performed by BD Accuri ${ }^{\text {Tim }}$ C6 (Becton Dickinson). For each sample, $2 \times 10^{4}$ events were acquired. Analysis was carried out by triplicate determination on at least three separate experiments.

\section{Western blot analysis}

U87MG cell lines were treated with RF-Id (IC:50) for $24 \mathrm{~h}, 48 \mathrm{~h}$ and $72 \mathrm{~h}$ or Bortezomib $(500 \mathrm{nM})$ for $24 \mathrm{~h}$ or a combination of Bortezomib and RF-Id for $24 \mathrm{~h}$ and $72 \mathrm{~h}$, respectively at $37{ }^{\circ} \mathrm{C}$. For cell extract preparation, cells were washed twice with ice-cold PBS, trypsinized and centrifuged for $30 \mathrm{~min}$ at $4{ }^{\circ} \mathrm{C}$ in $1 \mathrm{ml}$ of lysis buffer $(1 \%$ Triton, $0.5 \%$ sodium deoxycholate, $0.1 \mathrm{NaCl}, 1 \mathrm{mM}$ EDTA, $\mathrm{pH}$ 7.5, $10 \mathrm{mM} \mathrm{Na} \mathrm{HPO}_{4}$, pH 7.4, $10 \mathrm{mM}$ PMSF, $25 \mathrm{mM}$ benzamidin, $1 \mathrm{mM}$ leupeptin, 0.025 units/ml aprotinin). Equal amounts of cell proteins were separated by SDSPAGE in a sample buffer $1 \times$ (Sample Buffer 5X: Tris $10 \mathrm{mg} / \mathrm{ml}$, SDS $30 \mathrm{mg} / \mathrm{ml}$, b-mercaptoethanol $0.15 \mathrm{ml}$, glycerol $0.3 \mathrm{ml}$, bromophenol blue), electrotransferred to nitrocellulose membrane. Membrane were washed in TBST (10 mM Tris, pH 8.0, $150 \mathrm{mM} \mathrm{NaCl}$, 0,05 \% Tween 20), and blocked with TBST supplemented with $5 \%$ nonfat dry milk. Then, membranes were incubate with primary antibodies in TBST and $5 \%$ nonfat dry milk, washed, and incubated with horseradish peroxidaseconjugated secondary antibodies. All primary Abs were used at a diluition of 1:1000, instead all secondary Abs were used at a diluition of 1:2000. Blots were then developed using enhanced chemiluminescence detection reagents ECL (Thermo Fisher Scientific, Rockford, IL) and exposed to x-ray film. All films were scanned by using Quantity One software (BioRad Chemi Doc).

\section{Flow cytometric analysis of mitochondrial potential (Mitotracker Red)}

Changes in mitochondrial membrane potential due to ROS generation was analyzed by flow cytometry by using Mitotracker Red CMXRos (INVITROGEN Carlsbad, California, Stati Uniti). Briefly, U87MG and LN229 cells were plated in 6-multiwell plates at the density of $2 \times 10^{5}$ cells/ well. After treatment, cells were detached, centrifuged at $1200 \mathrm{~g}$ for $5 \mathrm{~min}$ and resuspended in PBS. Mitotracker Red probe was added at a final concentration of $100 \mathrm{nM}$. The latter does not emit fluorescence if it is not internalized in living cells. Mitotracker Red is oxidised in presence of ROS and emits a red fluorescence (FL2 channel) directly proportional to the potential of mitochondrial membrane. After the incubation with probe for $20 \mathrm{~min}$ at room temperature in the dark, cells were centrifuged, resuspended and analysed by BD Accuri ${ }^{\text {Tix }}$ C6. For each sample, 
20,000 events were acquired. Analysis was carried out by triplicate determination on at least three separate experiments.

\section{Flow cytometric analysis of autophagy}

Autofagy was analyzed by flow cytometry by using monodansylcadaverine (MDC)(Sigma-Aldrich, Saint Louis, Missouri, Stati Uniti) staining. MDC is an auto-florescent agent used as a selective marker for autophagic vacuoles (AVOs) and especially autolysosomes. U87MG cells were plated in 6-multiwell plates at the density of $2 \times 10^{5}$ cells/ well. After $72 \mathrm{~h}$ of treatment cells were incubated with $50 \mu \mathrm{M}$ of $\mathrm{MDC}$ in PBS $1 \mathrm{x}$ at $37^{\circ} \mathrm{C}$ for $15 \mathrm{~min}$. After the incubation the cells were washed twice in PBS $1 \times$, trypsinized and resuspended in $500 \mu \mathrm{l}$ of PBS $1 \times$. Analysis was performed by flow cytometric (BD Accuri ${ }^{\mathrm{Tm}}$ C6). The fluorescent emissions were collected through FL1 channel. For the quantitative evaluation of MDC, BD Accuri ${ }^{\text {Ts }}$ C6 software (Becton Dickinson) was used to calculate MFIs. The MFIs were calculated by the formula (MFI treated/MFI control), where MFI treated is the fluorescence intensity of cells treated with the various compounds and MFI control is the fluorescence intensity of untreated and unstained cells. For each sample, 20,000 events were acquired. Analysis was carried out by triplicate determination on at least three separate experiments.

\section{RNA extraction and Taqman Human Apoptosis Array- Real-Time-PCR}

Total RNA was prepared from U87MG cells according to mirVana PARIS (Ambion) protocol. In details, cells were centrifuged at 1,500 rpm for $5 \mathrm{~min}$; the pellets obtained were placed on ice and then resuspended in $300 \mu \mathrm{l}$ of Disruption Buffer. Successively, an equal volume of Denaturing Buffer (previously set at $37{ }^{\circ} \mathrm{C}$ ) was added to the pellets and they were incubated in ice for 5-10 $\mathrm{min}$. Then, Phenol-chloroform was added in the tube in a volume equal to the total volume and centrifugated at 10,000 rcf for $5 \mathrm{~min}$. After centrifugation, the aqueous phase was collected and a volume of absolute ethanol equal to 1.25 times that of the collected volume was added. Then $700 \mu \mathrm{L}$ at a time were collected, applied in Filter Cartridge and centrifuged at 10,000 rcf for $5 \mathrm{~min}$. $700 \mu \mathrm{L}$ of Wash Solution 1 were added on each Filter Cartridge, followed by centrifugation at 10,000 rcf for $40 \mathrm{~s}$, later two washings with $500 \mu \mathrm{l}$ of Wash Solution 2 were performed. Finally, $50 \mu \mathrm{l}$ of Eluition Buffer (preheated at $95^{\circ} \mathrm{C}$ ) were added to the Filter Cartridge, previously placed on new tubes. Then, the samples were quantized to Nanodrop (Technologies Inc., Wilmington, DE). The cDNA was obtained by using QuantiTect Reverse Transcription Kit, (Quiagen) according to the manufacturer's instructions. PCR products for all the genes tested were assessed in triplicate wells using TaqMan pre-developed assay reagents. The arithmetic standard normalization procedures recommended by the Data Assist software for microarray data were followed. In brief, data transformation was corrected for the signal from the three endogenous controls (18S, ACTB, GAPDH). Per card (mean) normalization accounted for the variability of each card by dividing all of the measurements on each card by the value of the 50th percentile. Per gene normalization accounted for the variability between probe sets for the three reporter genes. The threshold cycle, Ct, was automatically assigned by the SDS2.2 software package (Applied Biosystems). Relative quantities (RQ) were determined using the equation $\mathrm{RQ}=2-\Delta \Delta \mathrm{Ct}$. All data were generated in triplicate (different TLDA plates) and expressed as the mean \pm SD. Differentially expressed genes were selected from the normalized data using a procedure known as significance analysis of microarrays, as installed in the SDS2.3 software package (Applied Biosystems). Genes were considered to be significant when their average fold change (FC) was $\leq-1.5$ or $\geq 1.5$, and statistically significant when the corresponding $p$ value was $\leq 0.05$. Two software programs were used to analyze the data, namely SDS RQ Manager 1.2 and DataAssist v.2.2 software (Applied Biosystems).

Taqman human apoptosis array contains 93 human genes in addition to 3 endogenous controls (18S, ACTB, GAPDH). Real-time quantitative PCR was performed on a ViiA7 ${ }^{\text {rm }}$ Real time PCR system (Applied Biosystems, Darmstadt, Germany). Relative expression of the transcripts was measured by using ViiA $7^{\text {TM }}$ Real-Time PCR software (Applied Biosystems, Darmstadt, Germany). Treated samples were normalized to the corresponding medium-only control.

\section{Immunoprecipitation}

Total protein extracts were subjected to immunoprecipitation with $2 \mu \mathrm{g}$ of anti-XIAP or anti-cIAP2 for $24 \mathrm{~h}$ at $4{ }^{\circ} \mathrm{C}$. Immune complexes were collected with $50 \mu \mathrm{l}$ of protein A-agarose for $16 \mathrm{~h}$ at $4{ }^{\circ} \mathrm{C}$. The protein A-agarose/immune complex was washed twice with cold PBS, resuspended in $20 \mu \mathrm{l}$ of SDS-loading buffer, heated to $95^{\circ} \mathrm{C}$ for $5 \mathrm{~min}$ and used for Western blotting analysis using anti-XIAP or antiCIAP2.

\section{Statistical analysis}

All data are expressed as mean + SD. Statistical analysis was performed by analysis of variance (ANOVA) with Neumann-Keul's multiple comparison test or KolmogorovSmirnov test where appropriate.

\section{Results}

Effects of RF-Id on the proliferation of GBM cells

In order to investigate the antitumor activity of the new benzoquinone derivatives, we evaluated the effects of RFId, RF-Idmet and embelin on cell growth of two human 
GBM cell lines (U87MG and LN229) after $24 \mathrm{~h}, 48 \mathrm{~h}$ and $72 \mathrm{~h}$ of treatment. Cell growth inhibition was evaluated by cell viability assay as described in "Materials and methods" and resulted time- and dose-dependent for all compounds. In details, after $72 \mathrm{~h}$ RF-Id and RF-Idmet induced $50 \%$ (IC:50) of growth inhibition at a concentration of 23.6 and $47.5 \mu \mathrm{M}$ in the U87MG and 77 and $100 \mu \mathrm{M}$ in LN229, respectively while IC:50 of embelin was $30 \mu \mathrm{M}$ in U87MG and $33 \mu \mathrm{M}$ in LN229 (Fig. 1).

On the other hand, NDGA, a natural 5-LOX inhibitor and its methylated derivative terameprocol inhibited $50 \%$ of cell growth at a concentration of 87 and $>50 \mu \mathrm{M}$ in U87MG and $>50 \mu \mathrm{M}$ in LN229, respectively, as reported in Table 1. In conclusion, RF-Id was more potent than its methylated derivative and embelin in inducing growth inhibition on U87MG cells.

\section{Effects of RF-Id on cell cycle modulation}

In order to study the molecular mechanisms of the antiproliferative activity of RF-Id, we performed cell cycle analysis by flow cytometry. On the basis of the IC:50 values, U87MG cells resulted more sensitive to the treatment with RF-Id and were selected for subsequent experiments. Cells were treated for $72 \mathrm{~h}$ with RF-Id and, subsequently, were stained with propidium iodide for $1 \mathrm{~h}$ and analyzed by flow cytometry. For each sample, the percentage of cells in each phase of the cell cycle (G0/G1-S-G2M) was calculated.

Cell cycle analysis showed that treatment with RF-Id induced an increase of S and G2/M cells and a decrease of G0/G1 (Fig. 2). In details, as reported in the histogram, the percentage of cells in $\mathrm{S}$ phase and G2/M was equal to 35 and $20 \%$, respectively, in the control while it increased
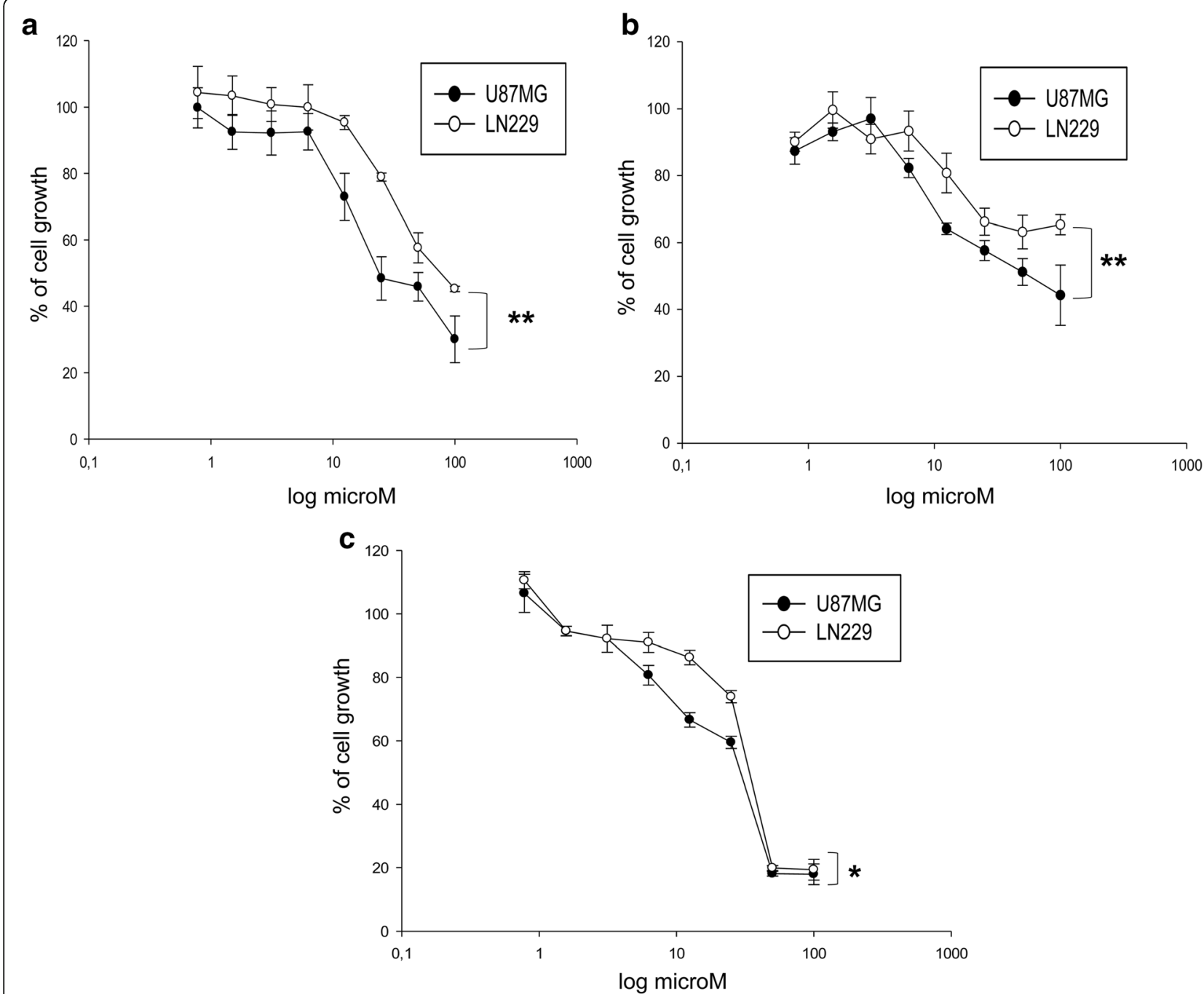

Fig. 1 Effects of RF-ld (a), RF-ldmet(b) and embelin(c) on cell growth inhibition. Human GBM cells U87MG and LN229 were seeded in serum-containing media in 96-well plates at the density of $2 \times 10^{3}$ cells/well. After $24 \mathrm{~h}$ incubation at $37^{\circ} \mathrm{C}$, cells were treated with increasing concentrations of RF-ld (a), RF-ldmet (b) and embelin (c) $(0,8-100 \mu \mathrm{M})$ for $72 \mathrm{~h}$. Cell viability was assessed by MTT assay as described in Material and methods. ${ }^{* *} p \leq 0.01$ 
Table 1 IC:50 values of the different compounds in U87MG and LN229 cells after $72 \mathrm{~h}$ of treatment

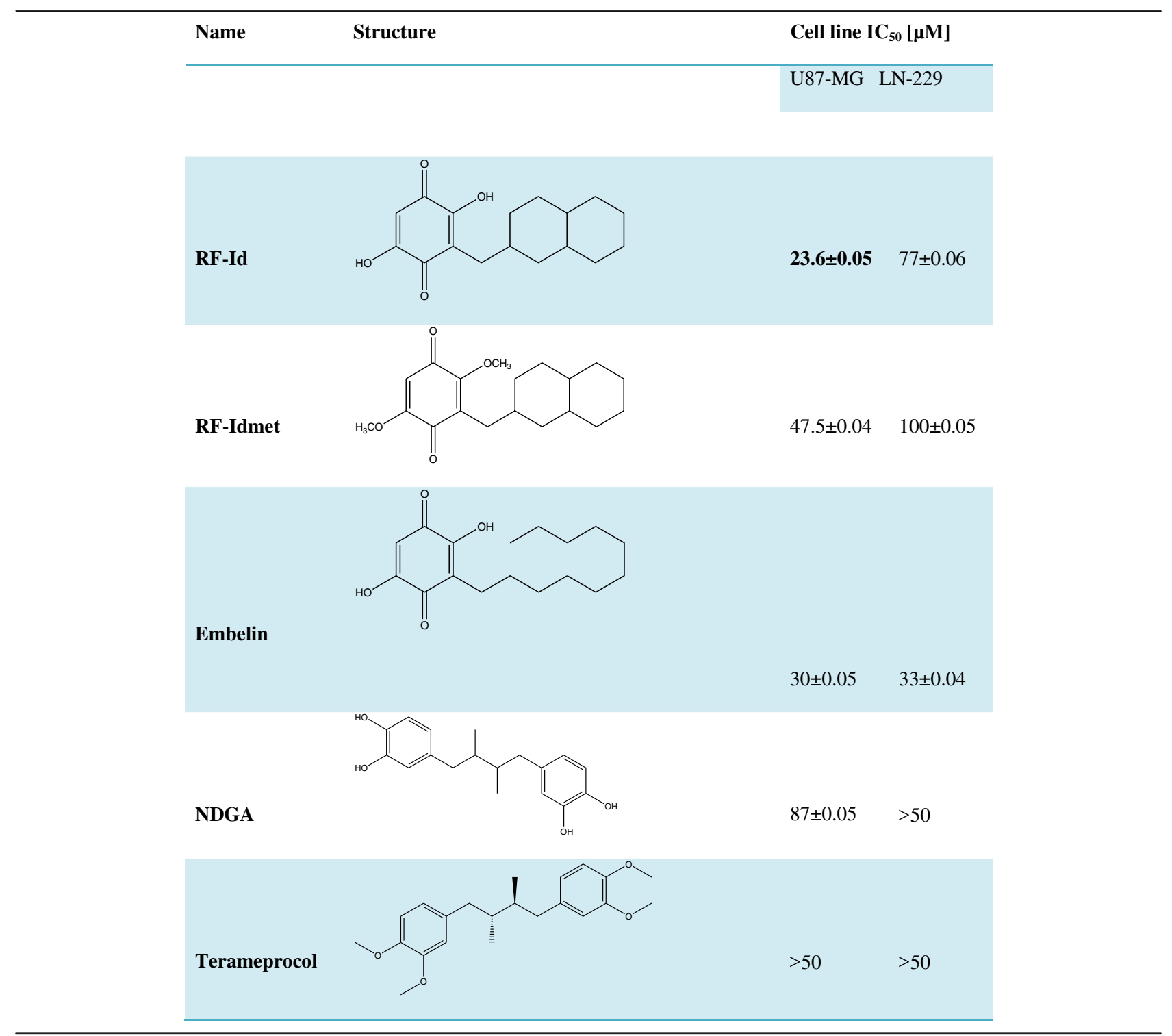

(about 45 and $30 \%$, respectively) with the treatment; on the other hand, the percentage of cells in G0/G1 decreased from 45 to $35 \%$ after treatment with RF-Id.

\section{Effects of RF-Id on apoptosis}

Subsequently, we evaluated the effects of RF-Id on apoptosis by flow cytometry. After $72 \mathrm{~h}$ of treatment, U87MG cells were stained with Annexin V-FITC and propidium iodide and analyzed by flow cytometry. As shown in Fig. 3, RF-Id induced about $30 \%$ of apoptosis compared to control cells (1,6\%); in details, $24 \%$ of the cells were in late apoptosis and $12 \%$ in early apoptosis. No significant effects were recorded on necrosis. In conclusion, RF-Id showed a significant pro-apoptotic effect.
In order to confirm the apoptotic effect induced by RF-Id on U87MG cells, we examined its effects on caspase cascade by Western blotting technique (Fig. 4). In details, the cells treated for 24, 48, $72 \mathrm{~h}$ as described in Materials and Methods, were lysed and proteic lysates were analyzed by Western blotting. After 24 and $48 \mathrm{~h}$ of treatment no significant effects on the expression of caspases was observed while after $72 \mathrm{~h}$ RF-Id induced an increase of procaspases $3,7,8$ and 9 and a significant increase of the cleaved fragments, indicative of caspase activation (Fig. 4). In addition, treatment with RF-Id did not alter the levels of p21 and p27 after 24 and $48 \mathrm{~h}$ while they significantly increased after $72 \mathrm{~h}$ (Fig. 4). This effect on p21 and p27 expression was likely due to a decrease of protein ubiquitination and consequently to p21 

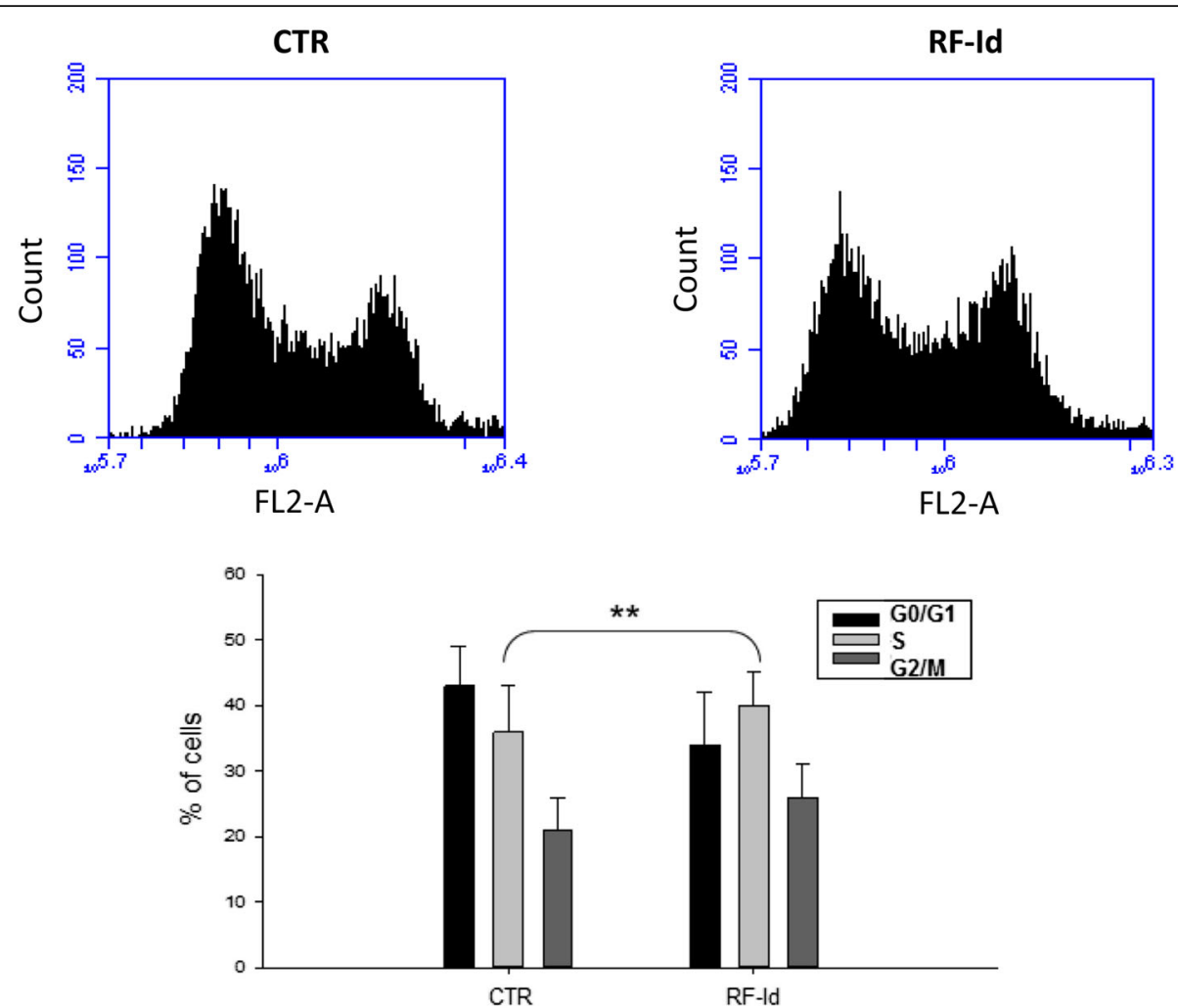

Fig. 2 Effects of RF-Id on cell cycle. U87-MG cells were treated for $72 \mathrm{~h}$ with IC:50 of RF-Id and subsequently were stained with propidium iodide for $1 \mathrm{~h}$ and analyzed by flow cytometry. For each sample, the percentage of cells in each phase of the cell cycle (G0 / G1-S-G2M) was calculated. The experiments were repeated three times giving always similar results. Bars, SDs. ** $p \leq 0.01$

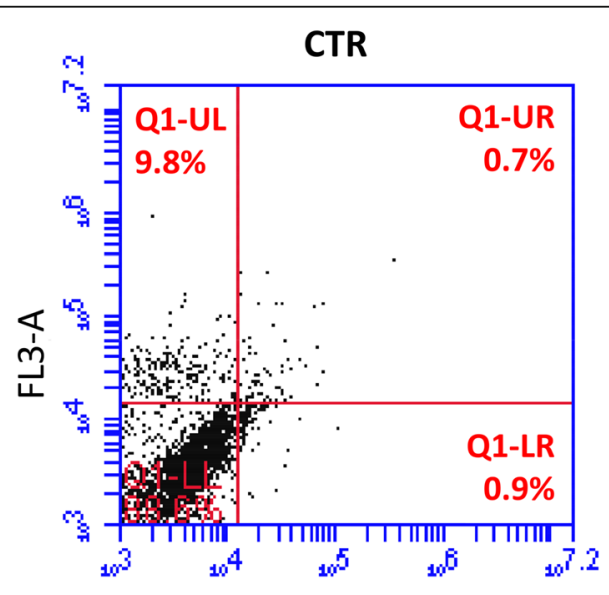

FL1-A

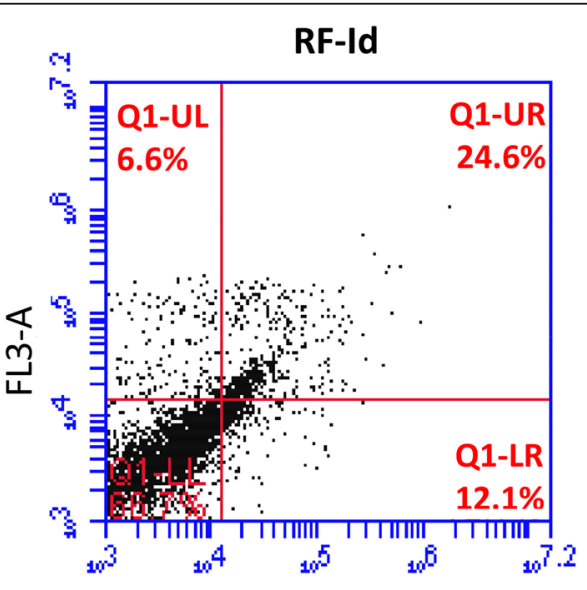

FL1-A

Fig. 3 Effects of RF-Id on apoptosis. U87 MG cells were not treated or treated with RF-Id IC:50 for 72 h. Apoptosis was evaluated by FACS analysis, after double cell labeling with propidium iodide (PI) and Annexin V-FITC. The lower left quadrants of each panel show the viable cells, which exclude PI and are negative for AnnexinV-FITC binding. The upper left quadrants contain the non-viable, necrotic cells, negative for Annexin V-FITC binding and positive for PI uptake. The lower right quadrants represent cells in early apoptosis that are Annexin V-FITC positive and PI negative. The upper right quadrants represent the cells in late apoptosis, positive for both Annexin V-FITC binding and for PI uptake. The experiments were performed at least three times and the results were always similar 


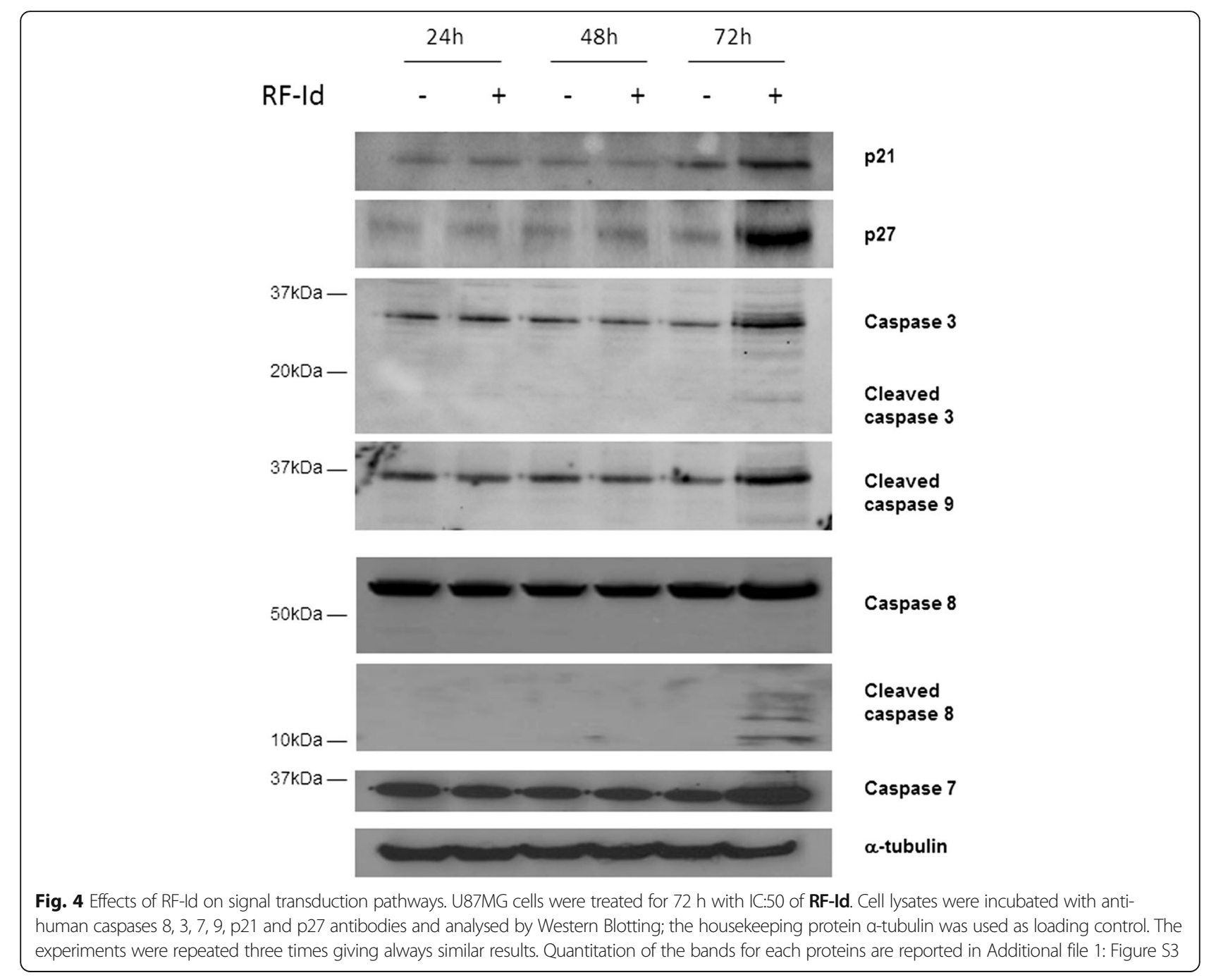

and p27 accumulation. In fact, we showed (Additional file 1: Figure S1) that after $72 \mathrm{~h}, \mathrm{Rf}-\mathrm{Id}$ treatment decreased ubiquitinated form of p21. In conclusion, RF-Id was able to induce apoptosis by a caspase-dependent mechanism.

\section{Effects of RF-Id on mitochondrial membrane potential and autophagy}

We evaluated the effects of RF-Id on mitochondrial membrane potential by flow cytometry. Cells were treated for $72 \mathrm{~h}$ at concentrations equal to IC:50 and stained with Mitotracker dye which localized in mitochondria and changed in according to mitochondrial membrane potential variations due to oxidative stress. RF-Id did not induce significant effects (110\% MFI) on the membrane potential of U87MG cells compared to control (100 \% MFI) (Fig. 5a). In addition, we evaluated the effects of RF-Id on autophagy.
In details, cells were treated for $72 \mathrm{~h}$ and subsequently were stained with MDC, specific marker for autophagosomes and analyzed by flow cytometry. Analysis of the data showed that treatment with RF-Id induced a slight increase of autophagy in U87MG (120 \% MFI) compared to control (100 \% MFI) (Fig. 5b).

\section{Identification of RF-Id regulated genes in apoptosis}

On the basis of the data demonstrating that RF-Id induced caspase-dependent cell death in U87MG cells, we assessed more globally the mechanisms involved in RFId-induced apoptosis using microarray analysis. Therefore, RNA was prepared from either untreated U87MG cells or cells exposed to RF-Id for $72 \mathrm{~h}$. Three biological replicates were performed per group. Data were normalized using the glyceraldehyde-3-phosphate dehydrogenase (GAPDH), ACTB and $18 \mathrm{~S}$ genes as internal control. After $72 \mathrm{~h}$ of treatment, differential gene expression 


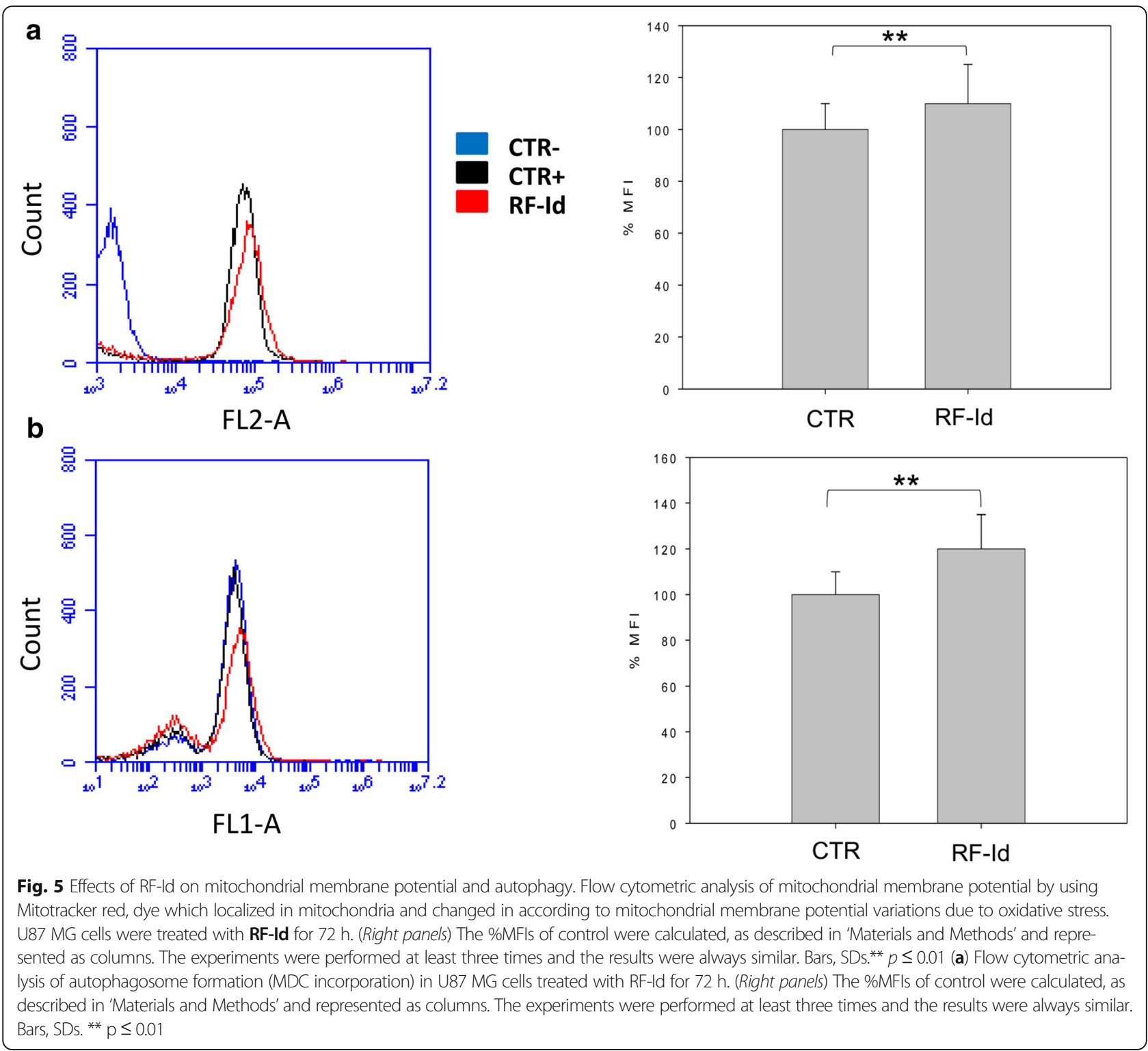

analysis revealed 10 significantly modulated transcripts (8 decreased and 2 increased) in RF-Id-treated cells compared to controls. In particular, BIRC2, BIRC4, BIRC5 and BIRC6, NFKB1, NFKBIA, CASP6 and BNIP3 were downregulated. At this time, CASP8 and $N F K B I Z$ were the only upregulated genes detected in this analysis (Fig. 6). Other genes did not show highly significant changes as reported in Additional file 1: Table S1. Intriguingly, most of the upregulated genes were associated to extrinsic pathway (CASP8) while downregulated genes belonged to $I A P$ family and $N F K B$ pathway.

\section{RF-Id inhibits XIAP-cIAP2 interaction}

Since RF-Id dowregulated genes belonged to IAP family and NFKB pathway and embelin inhibits the X-linked inhibitor of apoptosis protein (XIAP) by binding to its
Baculovirus Inhibitor of apoptosis protein Repeat (BIR) domain, we investigated the action mechanism of the compound. Recent evidence showed that XIAP stabilizes c-IAP2 at the protein level by inhibiting its autoubiquitination and the increased expression of c-IAP2 enhances the phosphorylation of IKB $\alpha$ that favours its subsequent proteasomal degradation leading to activation of the canonical NFkB pathway. In order to investigate if RF-Id disrupts XIAP-cIAP2 complex by inhibiting NFKB pathway, we evaluated the effects of RF-Id on either XIAP, cIAP2 and XIAP -CIAP2 complex expression and on IKK $\alpha / \beta$, IKB $\alpha$ and NFkB activation and expression. After $72 \mathrm{~h}$ RFId induced an increase of c-IAP2, a decrease of XIAP and significantly reduced the complex (Fig. 7a). Probably, RF-Id reduced XIAP by increasing its degradation, since bortezomib blocked RF-Id mediated-XIAP degradation and 


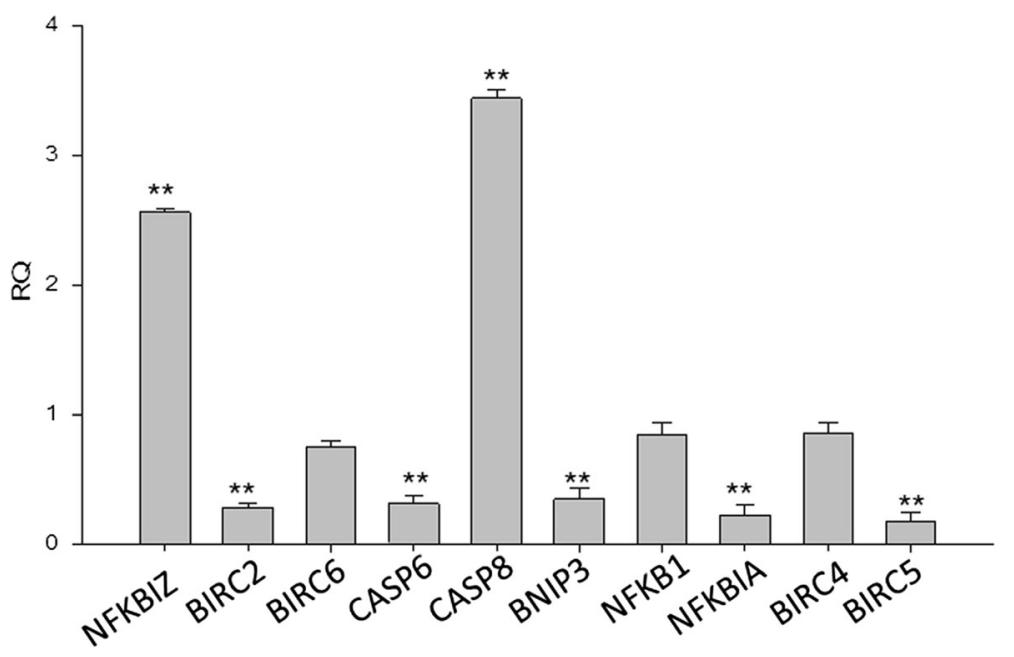

Fig. 6 RF-Id -regulated genes in U87MG cells. RNA was prepared from unexposed U87MG cells and exposed to RF-Id for 72 h. Data were normalized using GAPDH, $18 \mathrm{~S}$ and ACTB genes as internal control. Three biological replicates were performed per group. Relative expression of the transcripts was measured by using ViiA7 ${ }^{\mathrm{T} M}$ Real-Time PCR software. Bars, SDs. ${ }^{* *} p \leq 0.01$

increased its expression. Moreover, RF-Id reduced IKK $\alpha / \beta$ and $\mathrm{IkB} \alpha$ phosphorilation by increasing $\mathrm{IKB} \alpha$ expression thus inhibiting NFkB (Fig. 7b). On the other hand, bortezomib antagonized the effects of RF-Id by increasing XIAPcIAP-2 complex and leading to IKK $\alpha / \beta$-mediated IkB $\alpha$ phosphorylation and degradation (Fig. 7b). Moreover, Rf-Id mediated both apoptosis and caspase activation through degradation of XIAP, that acts as apoptosis inhibitor by binding caspases 9, 3 and 7. Bortezomib antagonized Rf-Idmediated caspase activation as it blocked XIAP degradation making XIAP able to inhibit both caspases activity and apoptosis identified as "DNA ladder" by agarose gel electrophoresis (Additional file 1: Figure S2).

In conclusion, RF-Id inhibited cIAP2-XIAP complex formation and IkB $\alpha$ degradation by leading to NFKB inhibition and caspase activation.

\section{Discussion}

Several benzoquinones have been found effective in treating some forms of cancer [17]; in details, it has been shown that these compounds act on cells by regulating numerous mechanisms, such as apoptosis, cell cycle [30], interacting with human-telomeric G-quadruplex DNA [31] or producing reactive oxygen species (ROS) [32]. Our group has been interested for a long time in synthesis and biological evaluation of anti-inflammatory and anti-cancer agents including quinone-based compounds [20-23]. Within the context of our investigations on quinone derivatives and on their possible therapeutic use, we recently studied the natural compound embelin and the synthetic derivative RF-Id [15, 19]. Previous research has demonstrated that embelin, a small inhibitor binding the Baculovirus Inhibitor of apoptosis protein Repeat (BIR) domain of the X-linked inhibitor of apoptosis protein (XIAP), suppressed proliferation of human glioma cells and induced apoptosis by inhibiting NF-kB signaling pathway. Our previous work revealed embelin as potent dual inhibitor of 5-LOX and microsomal prostaglandin $E_{2}$ synthase (mPGES)-1 with $\mathrm{IC}_{50}$ values of 60 and $200 \mathrm{nM}$ in cell-free assays, respectively. Moreover RF-Id, demonstrated an improved efficiency against 5-LOX in human neutrophils $\left(\mathrm{IC}_{50}=580 \mathrm{nM}\right)$ and in vivo anti-inflammatory activity.

The high potency on 5-LOX and the promising in vivo efficiency of synthesized compound prompted us to investigate the RF-Id antiproliferative effects in GBM tumor cell lines.

We showed that RF-Id had two major time-dependent in vitro consequences on U87-MG cells. This compound modulated cell cycle arrest and drove cells to programmed cell death by inhibiting cIAP2-XIAP complex formation and $I k B \alpha$ degradation and leading to $N F k B$ pathway inactivation.

First, we found that RF-Id was more potent than its methylated derivative and embelin in inducing growth inhibition on GBM cells, in particular on U87MG cells.

In order to study the molecular mechanisms of the antiproliferative activity of RF-Id, we performed cell cycle and apoptosis analysis by flow cytometry. In details, after $72 \mathrm{~h}$ RF-Id induced about $30 \%$ apoptosis and cell death was mediated by caspases and occurred through a ROSindependent mechanism. In fact, the compound induced a significant cleavage of the initiator caspases 8,9 , and of effector caspases 3 and 7 but did not induce significant alterations of the mitochondrial membrane potential associated to increased ROS production in mitochondria. Moreover, the compound induced an increase in the percentage of cells in G2 and S phase that occurred in parallel to an increase of the expression of p21 and p27. The increase of 


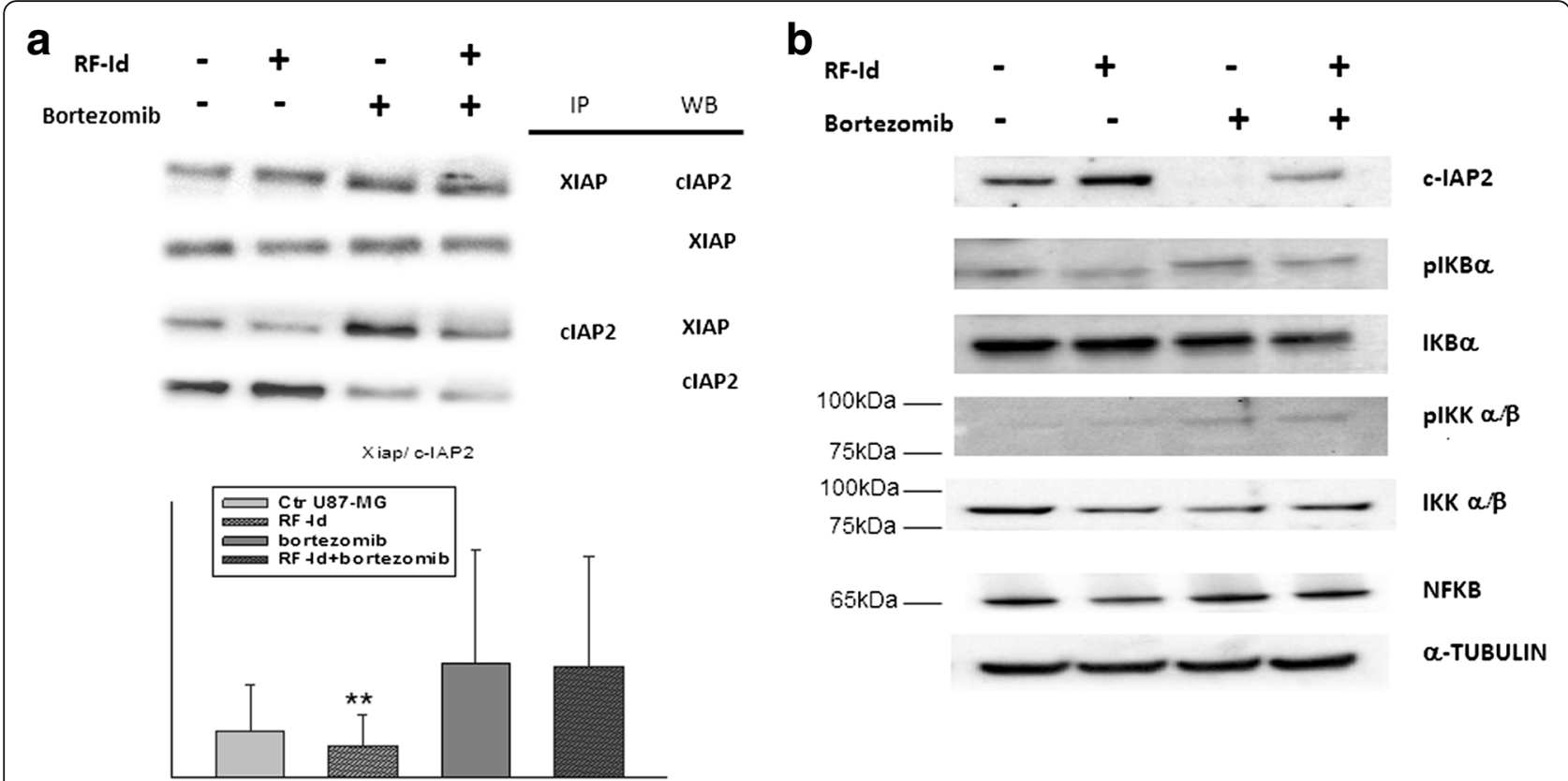

Fig. 7 RF-Id inhibits XIAP-CIAP2 interaction and NFKB activation. Total protein extracts were subjected to immunoprecipitation with $2 \mu \mathrm{g}$ of anti-XIAP or anti-CIAP2 for $24 \mathrm{~h}$ at $4{ }^{\circ} \mathrm{C}$. Immune complexes were collected with $50 \mu \mathrm{l}$ of protein A-agarose for $16 \mathrm{~h}$ at $4{ }^{\circ} \mathrm{C}$. The protein A-agarose/immune complex was washed twice with cold PBS, resuspended in $20 \mu$ l of SDS-loading buffer, heated to $95^{\circ} \mathrm{C}$ for 5 min and used for Western blotting analysis using antiXIAP or anti-CIAP2. Representation of the C-IAP2 and XIAP complexes was expressed as the mean of the ratio between the relative intensities of the bands associated with the C-IAP2/XIAP complexes versus the bands associated with total C-IAP2 and XIAP, respectively. The intensities of the bands were expressed as arbitrary units when compared to that of the untreated cells. Error bars showed standard deviation from the mean in at least three independent experiments. Bars, SDs.** $p \leq 0.01$ (a). U87MG cells were treated for $72 \mathrm{~h}$ with IC:50 of RF-Id or $500 \mathrm{nM}$ Bortezomib for $24 \mathrm{~h}$ or a combination of RF-Id and Bortezomib. Cell lysates were incubated with anti-human c-IAP2, plKKa/ $\beta$, $I \mathrm{KKa} / \beta, \mathrm{pIKBa}, \mathrm{KKBa}$ and $\mathrm{NFKB}$ antibodies and analysed by Western Blotting; the housekeeping protein a-tubulin was used as loading control. The experiments were repeated three times giving always similar results. Quantitation of the bands for each proteins are reported in Additional file 1: Figure S4 (b)

p21 and p27 could be due to a decrease of protein ubiquitination and hence, a reduced degradation rather than to an increase of gene transcription. In fact, XIAP or c-IAP2 may act as E3-ubiquitin ligases promoting the degradation of CDK inhibitors, p21 and p27 [33]. We recorded a late increase of p21 and p27 expression after treatment with Rf-Id that could be due to a decrease of protein ubiquitination and consequently to p21 and p27 accumulation. This effect on p21 and p27 expression can be likely ascribed to RF-Id that induces XIAP degradation and c-IAP2 inhibition, blocks their ubiquitin ligases activity and reduces p21 and p27 degradation by proteosome. As shown in Additional file 1 , we found a decrease of ubiquitinated form of $\mathrm{p} 21$ after $72 \mathrm{~h}$ from the beginning of Rf-Id treatment.

In addition, RF-Id induced only a slight $20 \%$ increase of autophagy that may be due to a blockage of the autophagic flow that causes an accumulation of MDC, marker of autophagosomes. The action mechanism of RF-Id was confirmed by performing apoptosis array. Data analysis, in fact, showed a significant upregulation of CASP8 and a downregulation of IAP family proteins (BIRC2, 4,5,6 and 7) and $N F \kappa B$ in cells treated with RFId for 72 h. Probably, RF-Id acts by inhibiting IAP family genes (XIAP, c-IAP1, c-IAP2) and NFKB pathway and inducing apoptosis through both intrinsic and extrinsic pathways thus, resulting in the amplification of the apoptotic signal.

Recent evidence showed that XIAP stabilizes c-IAP2 at the protein level by inhibiting its auto-ubiquitination and the increased expression of c-IAP2 enhances the phosphorylation of IKB $\alpha$ that favours its subsequent proteasomal degradation leading to activation of the canonical $N F k B$ pathway [34, 35]. In fact, we hypothesized that RF-1d by inhibiting XIAP could decrease c-IAP2, but we found that c-IAP2 was indeed increased. Based on these results, we suggest that RF-Id could disrupt XIAP-cIAP2 binding by inducing XIAP ubiquitination and proteosome-mediated degradation as bortezomib blocked RF-Id-mediated XIAP degradation and increased its expression. On this light, RFId could bind and stabilize c-IAP2 at the protein level by displacing XIAP but inhibits its activity as caspase inhibitor by blocking BIR3 domain of c-IAP2, as a consequence we found that RF-Id activated caspases 3, 7, 8 and 9. Binding of the XIAP RING domain to c-IAP2 is a pre-requisite for stabilization of c-IAP2, even though the RING activity may be defective, suggesting that occupation of BIR domains 2 


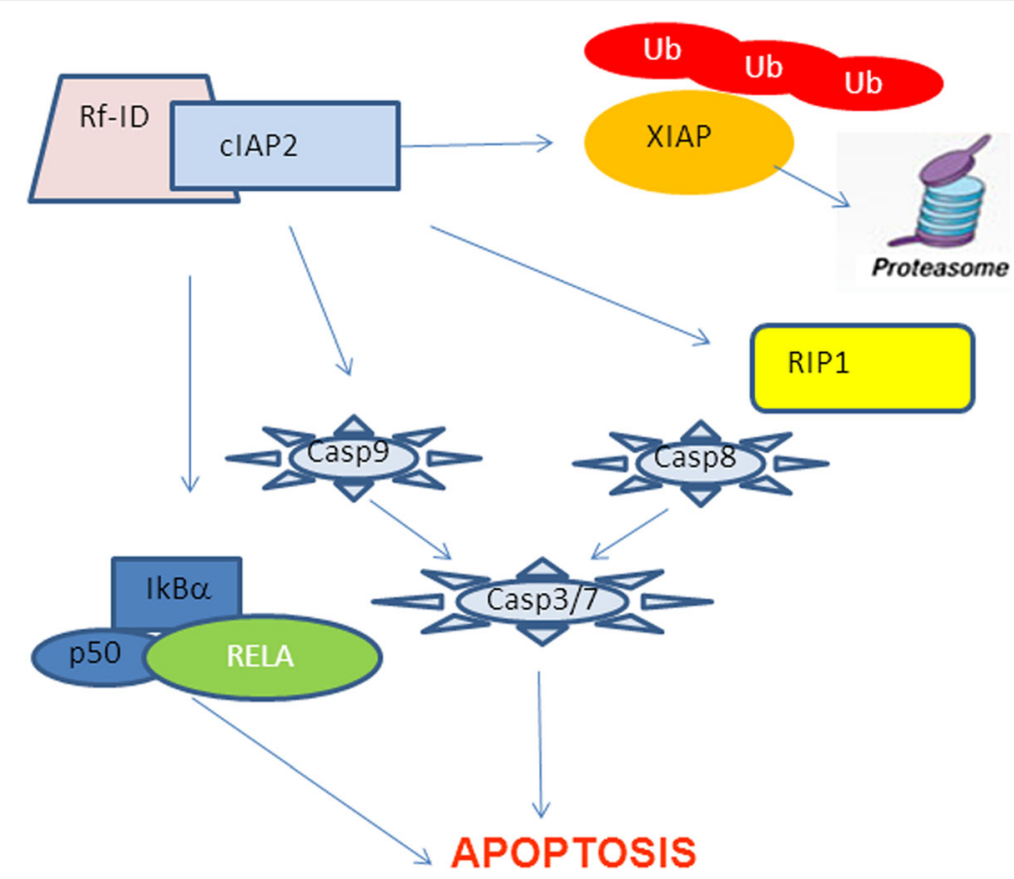

Fig. 8 RF-Id inhibits CIAP2 and XIAP activity and NFKB pathway. RF-Id disrupts XIAP-CIAP2 binding by inducing XIAP ubiquitination and proteosomemediated degradation. Moreover, RF-Id stabilizes C-IAP2 at the protein level but inhibits its activity as caspases inhibitor by blocking BIR3 domain of CIAP2, thus activating caspases 3,7, 8 and 9. Moreover, blockade of CIAP2-XIAP complex formation increases IkBa expression leading to NFkB inactivation and apoptosis induction

and 3 on c-IAP2 by XIAP through its RING finger guarantees the ensuing increase in c-IAP2 stability. Protein interactions occur through binding of BIR2 and BIR3 domains of c-IAP2 with the RING finger of XIAP. RF-Id probably binds BIR3 domain of c-IAP2 and stabilizes it by blocking its degradation but inhibits its caspase inhibitor activity so that the BIR-bound caspases are released and reactivated; in the same time, Rf-Id displaces XIAP that undergoes to auto-ubiquitination and is degraded via proteosome. Moreover, Rf-Id acts inhibiting c-IAP1 while c-IAP2 undergoes to a posttranscriptional regulation; it increases because its degradation is reduced. In fact, it is reported that cells from c-IAP1(-/-) mice express markedly elevated levels of c-IAP2 protein in the absence of increased c-IAP2 mRNA. Transient transfection studies with wild-type and E3-defective cIAP1 revealed that c-IAP2 is a direct target for c-IAP1mediated ubiquitination and subsequent degradation [36].

Blockade of cIAP2-XIAP complex formation increased IkB $\alpha$ expression leading to NFKB inhibition and apoptosis induction by reducing survivin and FLIP, a caspase 8 inhibitor as confirmed by microarray analysis (Fig. 8).

On the other hand, bortezomib antagonized the effects of RF-Id by increasing XIAP-cIAP2 complex leading to IKK $\alpha / \beta$-mediated IKB $\alpha$ phosphorylation and $\mathrm{NF}_{\kappa} B$ activation as it blocked RF-Id-mediated XIAP degradation [37]. As reported in the literature [38], Bortezomib downregulated cIAP2 expression, probably by a NFKB-independent mechanism. Moreover, Rf-Id mediated both apoptosis and caspase activation through degradation of XIAP, that acts as apoptosis inhibitor by binding caspases 9,3 and 7. Bortezomib antagonized Rf-Id-mediated caspase activation as it blocked XIAP degradation making XIAP able to inhibit caspase-mediated apoptosis.

\section{Conclusions}

RF-Id induced apoptosis associated with modulation of cell cycle on U87MG by inducing XIAP degradation and inhibiting NFkB pathway. In conclusion, RF-Id could represent a new therapeutic strategy in GBM, due to its highly lipophilic structure, able to target multiple intracellular components.

\section{Additional file}

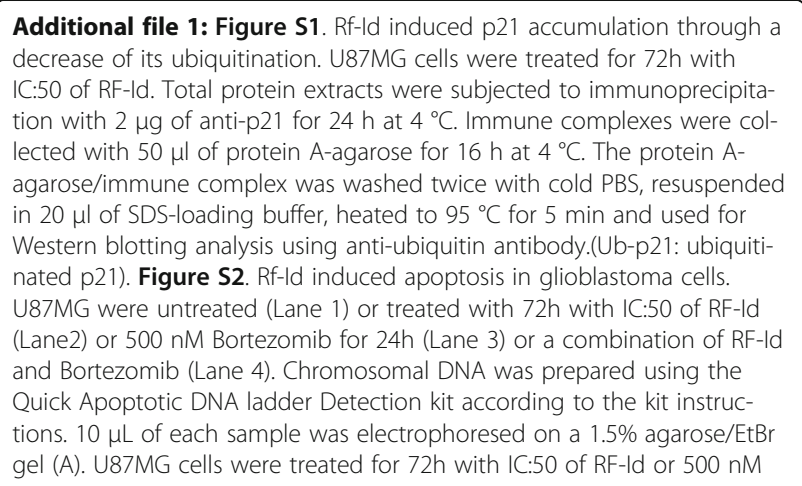


Bortezomib for 24h or a combination of RF-ld and Bortezomib. Cell ly sates were incubated with anti-human XIAP, caspase 3 and 7 antibodies and analysed by Western Blotting; the housekeeping protein a-tubulin was used as loading control. The experiments were repeated three times giving always similar results (B). Figure S3 Effects of RF-Id on signal transduction pathway. The intensities of the bands were expressed as arbitrary units when compared to that of the untreated cells and normalized for a-tubulin. Error bars showed standard deviation from the mean in at least three independent experiments. Bars, SDs.** $p \leq 0.01$ Figure S4 RF-Id inhibits XIAP-CIAP2 interaction and NFKB activation. The intensities of the bands were expressed as arbitrary units when compared to that of the untreated cells and normalized for a-tubulin. Error bars showed standard deviation from the mean in at least three independent experiments. Bars, SDs.** $p \leq 0.01$. (DOC $654 \mathrm{~kb})$

\section{Acknowledgements}

Not applicable.

\section{Funding}

This work was supported in part by the grant PON 03 PE_00060_07 (MIUR) Sviluppo pre-clinico di nuove terapie e di strategie innovative per la produzione di molecole ad azione farmacologica.

\section{Availability of data and materials}

Data sharing not applicable to this article as no datasets were generated or analysed during the current study.

\section{Authors' contributions}

RF and MC conceived, designed the study, and wrote the paper. SZ designed the experiment, analyzed and interpreted the data. CS, MS, performed the experiment CS, MDR, DI gave technical support and conceptual advice. All authors read and approved the final manuscript.

\section{Competing interests}

The authors declare that they have no competing interests.

\section{Consent for publication}

Not applicable.

\section{Ethics approval and consent to participate}

Not applicable.

Received: 23 August 2016 Accepted: 6 October 2016

Published online: 22 October 2016

\section{References}

1. Addeo R, Caraglia M. Combining temozolomide with other antitumor drugs and target-based agents in the treatment of brain metastases: an unending quest or chasing a chimera? Expert Opin Investig Drugs. 2011;20(7):881-95.

2. Stupp R, Mason WP, van den Bent MJ, Weller M, Fisher B, Taphoorn MJ, Belanger K, Brandes AA, Marosi C, Bogdahn U, Curschmann J, Janzer RC, Ludwin SK, Gorlia T, Allgeier A, Lacombe D, Cairncross JG, Eisenhauer E, Mirimanoff RO, EuropeanOrganisation for Research and Treatment of Cancer Brain Tumor and RadiotherapyGroups; National Cancer Institute of Canada Clinical Trials Group. Radiotherapyplus concomitant and adjuvant temozolomide for glioblastoma. N Engl J Med. 2005;352(10):987-96.

3. De Rossi A, Rossi L, Laudisi A, Sini V, Toppo L, Marchesi F, Tortorelli G, Leti M, Turriziani M, Aquino A, Bonmassar E, De Vecchis L, Torino F. Focus on Fotemustine. J Exp Clin Cancer Res. 2006;25(4):461-8.

4. Malhaire JP, Lucas B, Simon H, Person H, Dam-Hieu P, Labat JP. Fotemustine (Muphoran) in 22 patients with relapses of high-grade cerebral gliomas. Bull Cancer. 1999;86(3):289-94.

5. Nieder C, Adam M, Molls M, Grosu AL. Therapeutic options for recurrent highgrade glioma in adult patients: recent advances. Crit Rev Oncol Hematol. 2006: 60(3):181-93.

6. Porru M, Zappavigna S, Salzano G, Luce A, Stoppacciaro A, Balestrieri ML, Artuso S, Lusa S, De Rosa G, Leonetti C, Caraglia M. Medical treatment of orthotopic glioblastoma with transferrin-conjugated nanoparticles encapsulating zoledronic acid. Oncotarget. 2014;5(21):10446-59.
7. Huncharek M, Muscat J. Treatment of recurrent high grade astrocytoma; results of a systematic review of 1,415 patients. Anticancer Res. 1998;18(2B): 1303-11.

8. Ishii K, Zaitsu M, Yonemitsu N, Kan Y, Hamasaki Y, Matsuo M. 5-lipoxygenase pathway promotes cell proliferation in human glioma cell lines. Clin Neuropathol. 2009;28(6):445-52.

9. Golubic M, Prayson RA, Vargo L, Bondar J, Barnett GH. Increased expression of 5-lipoxygenase in glioblastoma multiforme. Adv Exp Med Biol. 2003;525:205-8.

10. Zhang L, Zhang WP, Hu H, Wang ML, Sheng WW, Yao HT, Ding W, Chen Z, Wei EQ. Expression patterns of 5-lipoxygenase in human brain with traumatic injury and astrocytoma. Neuropathology. 2006;26(2):99-106.

11. Nathoo N, Prayson RA, Bondar J, Vargo L, Arrigain S, Mascha EJ, Suh JH, Barnett GH, Golubic M. Increased expression of 5-lipoxygenase in highgrade astrocytomas. Neurosurgery. 2006;58(2):347-54.

12. Wang X, Chen Y, Zhang S, Zhang L, Liu X, Zhang L, Li X, Chen D. Coexpression of COX-2 and 5-LO in primary glioblastoma is associated with poor prognosis. J Neurooncol. 2015;125(2):277-85.

13. Lim JY, Oh JH, Jung JR, Kim SM, Ryu CH, Kim HT, Jeun SS. MK886-induced apoptosis depends on the 5-LO expression level in human malignant glioma cells. J Neurooncol. 2010;97(3):339-46.

14. Grossman SA, Ye X, Peereboom D, Rosenfeld MR, Mikkelsen T, Supko JG Desideri S. Adult Brain Tumor Consortium. Phase I study of terameprocol in patients with recurrent high-grade glioma. Neuro Oncol. 2012;14(4):511-7.

15. Petronzi C, Filosa R, Peduto A, Monti MC, Margarucci L, Massa A, Ercolino SF, Bizzarro V, Parente L, Riccio R, de Caprariis P. Structure-based design, synthesis and preliminary anti-inflammatory activity of bolinaquinone analogues. Eur J Med Chem. 2011:46:488-96.

16. Filosa R, Peduto A, Aparoy A, Schaible AM, Luderer S, Krauth V, Petronzi C, Massa A, de Rosa M, Reddanna P, Werz O. Discovery and biological evaluation of novel 1,4-benzoquinone and related resorcinol derivatives that inhibit 5lipoxygenase. Eur J Med Chem. 2013;67:269-79.

17. Petronzi C, Festa M, Peduto A, Castellano M, Marinello J, Massa A, Capasso A, Capranico G, La Gatta A, De Rosa M, Caraglia M, Filosa R. Cyclohexa-2,5diene-1,4-dione-based antiproliferative agents: design, synthesis, and cytotoxic evaluation. J Exp Clin Cancer Res. 2013;32:24-35.

18. Schaible AM, Filosa $R$, Traber $H$, Temml V, Noha SM, Peduto A, Weinigel $C$ Barz D, Schuster D, Werz O. Potent inhibition of human 5-lipoxygenase and microsomal prostaglandin E2 synthase-1 by the anti-carcinogenic and antiinflammatory agent embelin. Biochem Pharmacol. 2013;86:476-86.

19. Schaible AM, Filosa R, Temml V, Krauth V, Matteis M, Peduto A, Bruno F, Luderer S, Roviezzo F, Di Mola A, de Rosa M, D’Agostino B, Weinigel C, Barz D, Koeberle A, Pergola C, Schuster D, Werz O. Elucidation of the molecular mechanism and the efficacy in vivo of a novel 1,4-benzoquinone that inhibits 5-lipoxygenase. Br J Pharmacol. 2014;171:2399-412.

20. Peduto A, Bruno F, Dehm F, Krauth V, de Caprariis P, Weinigel C, Barz D, Massa A, De Rosa M, Werz O, Filosa R. Further studies on ethyl 5-hydroxyindole-3-carboxylate scaffold: design, synthesis and evaluation of 2phenylthiomethyl-indole derivatives as efficient inhibitors of human 5lipoxygenase. Eur J Med Chem. 2014;81(6):492-8.

21. Filosa R, Peduto A, Schaible AM, Krauth V, Weinigel C, Barz D, Petronzi C, Bruno F, Roviezzo F, Spaziano G, D’Agostino B, De Rosa M, Werz O. Novel series of benzoquinones with high potency against 5-lipoxygenase in human polymorphonuclear leukocytes. Eur J Med Chem. 2015;94(2):132-9.

22. Schaible AM, Filosa R, Krauth V, Temml V, Pace S, Garscha U, Liening S, Weinigel S, Rummler S, Schieferdecker S, Nett M, Peduto A, Collarile S, Scuotto M, Roviezzo F, Spaziano G, de Rosa M, Stuppner H, Schuster D, D'Agostino B, Werz O. The 5-lipoxygenase inhibitor RF-22c potently suppresses leukotriene biosynthesis in cellulo and blocks bronchoconstriction and inflammation in vivo. Biochem Pharmacol. 2016;16:30073-9.

23. Peduto A, Krauth V, Collarile S, Dehm F, Ambruosi M, Belardo C, Guida F, Massa A, Esposito V, Maione S, de Rosa M, Werz O, Filosa R. Exploring the role of chloro and methyl substitutions in 2-phenylthiomethyl-benzoindole derivatives for 5-LOX enzyme inhibition. Eur J Med Chem. 2016;108(1):466-75.

24. Peduto A, Pagano B, Petronzi C, Massa A, Esposito V, Virgilio A, Paduano F, Trapasso F, Fiorito F, Florio S, Giancola C, Galeone A, Filosa R. Design, synthesis, biophysical and biological studies of trisubstituted naphthalimides as G-quadruplex ligands. Bioorg Med Chem. 2011;19:6419-29.

25. Filosa R, Peduto A, Micco SD, de Caprariis P, Festa M, Petrella A, Capranico $G$, Bifulco $G$. Molecular modelling studies, synthesis and biological activity of a series of novel bisnaphthalimides and their development as new DNA topoisomerase II inhibitors. Bioorg Med Chem. 2009;17:13-24. 
26. Peduto A, More V, de Caprariis P, Festa M, Capasso A, Piacente S, de Martino L, de Feo V, Filosa R. Synthesis and cytotoxic activity of new $\beta$-carboline derivatives. Mini-Rev Med Chem. 2011;11:486-91.

27. Wang A, Zhang B, Zhang J, Wu W, Wu W. Embelin-induced brain glioma cell apoptosis and cell cycle arrest via the mitochondrial pathway. Oncol Rep. 2013;29(6):2473-8.

28. Park SY, Lim SL, Jang HJ, Lee JH, Um JY, Kim SH, Ahn KS, Lee SG. Embelin induces apoptosis in human glioma cells through inactivating NF-KB. J Pharmacol Sci. 2013;121(3):192-9.

29. Siegelin MD, Gaiser T, Siegelin Y. The XIAP inhibitor Embelin enhances TRAlL-mediated apoptosis in malignant glioma cells by down-regulation of the short isoform of FLIP. Neurochem Int. 2009;55(6):423-30.

30. Khaw AK, Sameni S, Venkatesan S, Kalthur G, Hande MP. Plumbagin alters telomere dynamics, induces DNA damage and cell death in human brain tumour cells. Mutat Res Genet Toxicol Environ Mutagen. 2015;793(11):86-95.

31. Salem AA, El Haty IA, Abdou IM, Mu Y. Interaction of human telomeric Gquadruplex DNA with thymoquinone: a possible mechanism for thymoquinone anticancer effect. Biochim Biophys Acta. 2015;1850(2):329-42.

32. Hong $Y$, Sengupta $S$, Hur W, Sim T. Identification of novel ROS inducers: quinone derivatives tethered to long hydrocarbon chains. J Med Chem. 2015;58(9):3739-50.

33. Metzger MB, Hristova VA, Weissman AM. HECT and RING finger families of E3 ubiquitin ligases at a glance. J Cell Sci. 2012;125(3):531-7.

34. Yang W, Cooke M, Duckett CS, Yang X, Dorsey JF. Distinctive effects of the cellular inhibitor of apoptosis protein C-IAP2 through stabilization by XIAP in glioblastoma multiforme cells. Cell Cycle. 2014;13(6):992-1005.

35. Selmi T, Alecci C, Dell' Aquila M, Montorsi L, Martello A, Guizzetti F, Volpi N, Parenti S, Ferrari S, Salomoni P, Grande A, Zanocco-Marani T. ZFP36 stabilizes RIP1 via degradation of XIAP and CIAP2 thereby promoting ripoptosome assembly. BMC Cancer. 2015;15(5):357.

36. Conze DB, Albert L, Ferrick DA, Goeddel DV, Yeh WC, Mak T, Ashwell JD. Posttranscriptional downregulation of C-IAP2 by the ubiquitin protein ligase C-IAP1 in vivo. Mol Cell Biol. 2005:25(8):3348-56.

37. Hideshima T, Ikeda H, Chauhan D, Okawa Y, Raje N, Podar K, Mitsiades C, Munshi NC, Richardson PG, Carrasco RD, Anderson KC. Bortezomib induces canonical nuclear factor-kappaB activation in multiple myeloma cells. Blood. 2009:114(5):1046-52.

38. Juvekar A, Manna S, Ramaswami S, Chang TP, Vu HY, Ghosh CC, Celiker MY, Vancurova I. Bortezomib induces nuclear translocation of IKBa resulting in gene specific suppression of NFKB-dependent transcription and induction of apoptosis in CTCL. Mol Cancer Res. 2011;9(2):183-94.

\section{Submit your next manuscript to BioMed Central and we will help you at every step:}

- We accept pre-submission inquiries

- Our selector tool helps you to find the most relevant journal

- We provide round the clock customer support

- Convenient online submission

- Thorough peer review

- Inclusion in PubMed and all major indexing services

- Maximum visibility for your research

Submit your manuscript at www.biomedcentral.com/submit

) Biomed Central 